\title{
Syntactic Ergativity in Light Verb Complements
}

\author{
BALTHASAR BICKEL and JOHANNA NICHOLS ${ }^{1}$ \\ University of California, Berkeley
}

\section{Unexpected Syntactic Ergativity}

Complementation is generally claimed to be the least likely construction to involve syntactically ergative pivots (Croft 1991, Dixon 1994, Manning 1996, Givón 1997, etc.). However, there is systematic syntactic ergativity precisely in complements in languages of the Kiranti family of Sino-Tibetan (Himalayas) and the Nakh-Daghestanian family (Caucasus). In these languages, certain verbs of modality, phase, and cognition agree with the $\mathrm{S}$ or $\mathrm{O}$ argument of their infinitive complement. Examples from Belhare (Kiranti, Sino-Tibetan; Nepal) are in (1): ${ }^{2}$

(1) a. $\varnothing$ khon-ma nui-ka.

[S] play-INF may-NPT:2[SG]S

'You may play.'

b. $\left[\begin{array}{lll}\varnothing & \varnothing & \text { lu-ma }\end{array}\right]$ nui-ka.

[A] [O] tell-INF may-NPT:2[SG]S

'You may be told.' or 'I/S/he may tell you.'

Impossible: 'You may tell him/her.'

The modal verb agrees in person with the $S$ (intransitive subject) in (1a), the $O$ (transitive object) in (1b). We will provisionally call this AGREEMENT CLIMBING. Agreement Climbing is SYNTACTICALLY, not morphologically, ergative. (2) shows Belhare verb agreement (also cf. Bickel 2001, in press). Agreement markers do not align $\mathrm{S}$ with $\mathrm{O}$ (or with $\mathrm{A}$ for that matter). The alignment patterns for all regular verbs, including nus- 'may', are variously three-way or neutral, depending on person,but nowhere ergative: first person agreement (underlined in (2) for clarity) is three-way; second person agreement is neutral (boldface in (2); the $-g a \sim-k a$ alternation is morphophonemic); third person agreement is three-way, with a trace of accusative alignement (compare zero-marked $\mathrm{S}$ forms with zeromarked $\mathrm{A}$ forms when the $\mathrm{O}$ is third person).

\footnotetext{
${ }^{1}$ For contact information see the authors' website: http://www.uni-leipzig.de/ autotyp

2 Apart from nus- 'may', another modal verb, khes- 'must' shows the same behavior, but also allows for impersonal constructions (similar to French il faut).
} 
Balthasar Bickel and Johanna Nichols

(2) Belhare verb agreement (singular number only; non-past forms)

\begin{tabular}{|c|c|c|c|c|}
\hline & $1 \mathrm{sgO}$ & $2 \mathrm{sgO}$ & $3 \mathrm{sgO}$ & intransitive (S) \\
\hline $1 \mathrm{sgA}$ & & 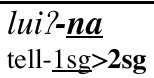 & $\begin{array}{l}\text { luit- } u-\underline{\eta} \\
\text { tell-3sgO-1sgA }\end{array}$ & $\begin{array}{l}\text { nui?-na } \\
\text { may-1sg }\end{array}$ \\
\hline $2 \operatorname{sgA}$ & $\begin{array}{l}\text { ka-lui-ka } \\
1 \text { sgO-tell-2sg }\end{array}$ & & $\begin{array}{l}\text { luit-u-ga } \\
\text { tell-3sgO-2sg }\end{array}$ & $\begin{array}{l}\text { nui-ka } \\
\text { may-2sg }\end{array}$ \\
\hline $3 \operatorname{sgA}$ & $\begin{array}{l}\text { mai-luyu } \\
\underline{1 \mathrm{sgO}-\text { tell }}\end{array}$ & $\begin{array}{l}n \text {-lui-ka } \\
\text { 3A-tell-2sg }\end{array}$ & $\begin{array}{l}\text { luit- } u \\
{[3 \operatorname{sgA}-] \text { tell-3sgO }}\end{array}$ & $\begin{array}{l}\text { nuyu } \\
{[3 \text { sgS-]may }}\end{array}$ \\
\hline
\end{tabular}

In the Chechen examples in (3), the gender prefix of the verb v.ieza, j.ieza 'should' is in agreement with the S/O of the infinitive: $S$ in (3a), O in (3b). (V and $\mathbf{J}$ are genders.)

(3) a. Muusaa $\varnothing$ c'a-v.agha v.ieza

Musa (V) [S] home-V.go.INF V.should 'Musa should go home.'

b. Muusaas $\varnothing$ disertaacii jaaz-j.a j.ieza

Musa.ERG [A] diss.(J).NOM write-J.AUX.INF J.should 'Musa should write (his) dissertation.'

Thus, in Chechen as in Belhare, Agreement Climbing is ergative. Furthermore, the ergativity is truly SYNTACTIC, not morphological. Now, only nominative can trigger agreement in Chechen and Ingush. But that fact does not make Agreement Climbing MORPHOLOGICALLY ergative. There are two arguments showing that the ergativity is syntactic:

(i) Only those nominatives that are in $\mathrm{S} / \mathrm{O}$ function can trigger Agreement Climbing. (4) shows an absolutive $\mathrm{A}$ in an accusative valence pattern (4a, b) with its causative (4c). The $\mathrm{O}$ of the causative infinitive (4c), but not the $\mathrm{A}$ of the noncausative (4b), can control Agreement Climbing. (Genitive case of Muusaan is assigned by d.ieza 'must'; see below.) This shows that Agreement Climbing is not mechanically with a nominative, but with an $\mathrm{S} / \mathrm{O}$ (provided the $\mathrm{S} / \mathrm{O}$ is nominative).

(4) Chechen qiera 'fear' < NOM LATIVE >

(Ingush likewise)

a. Muusaa sox qoeru

Musa.NOM 1SG.LAT fear.INF

'Musa is afraid of me.'

b. *Muusaan [ $\varnothing$ sox qiera ] v.ieza

Musa.GEN [A] 1SG.LAT fear.INF V.must

'Musa is supposed to fear me.'

c. "'Muusaan [ø Ahwmad sox qieriita ] v.ieza

Musa.GEN [A] Ahmed.NOM 1SG.LAT fear-CAUS.INF V.must

'Musa must instill fear of me in Ahmed. M must make A fear me.'

[Semantically odd but syntactically OK.] 
(ii) Chechen and Ingush have the morphological means to assign nominative case to an A if the syntax ever sought an A controller. The auxiliary verb regularly assigns subject cases in Nakh, and progressive auxiliaries change an oblique subject case to nominative (see Conathan 2001). (5a) from Ingush shows that 'read' is transitive. ( $5 \mathrm{~b}$ ) shows that the progressive auxiliary 'be' assigns nominative (not ergative) case to the subject:

(5) a. Muusaaz haara denna kinashjka diesh. Musa.ERG every day.DAT book.NOM D.read

'Musa reads a book every day.'

b. Muusaa kinashjka dieshazh vy.

Musa.NOM book.NOM D.read V.be.PRES

'Musa is reading a book.'

The progressive could surely function as an antipassive if the syntax required antipassivization. Evidently, therefore, the syntax of Chechen-Ingush infinitive complementation is uncoercedly ergative.

Apart from this syntactic ergativity of agreement climbing in complementation, Belhare has syntactic ergativity only in internal-head relativization (Bickel 2001 and in press), but in no other construction. Chechen and Ingush seem to have none at all.

\section{Common Assumptions about the Distribution of Syntactic Ergativity}

These facts challenge common assumptions in the literature, indicated for example in the following statements:

Whenever Secondary concepts of the first variety [= predicates like 'can', 'might', 'not', 'begin', 'finish', 'continue', 'try' - BB\&JN] are realized as lexical verbs, taking an object complement clause construction which involves another verb, the two verbs must have the same subject ( $\mathrm{S}$ or $\mathrm{A}$ ) irrespective of whether the language is accusative or ergative at morphological and/or syntactic levels. (Dixon 1994:135)

The control of Equi-NP-deletion (or coreference) in complement clauses is one of the least likely behavior-and-control features to show ergative-absolutive control. (Givón 1997:35)

A hierarchy of contexts for decreasing likelihood of syntactic ergativity, drawn from the literature, is shown in (6). Supporting subhierarchies are summarized in (7). (We are not aware of any empirical test of this hierarchy. We are beginning such a survey now as part of the AUTOTYP research program.) 
Balthasar Bickel and Johanna Nichols

$$
\begin{aligned}
& \text { 1: verb agreement } \\
& \text { 2: relativization, focalization, interrogation, quantifier launch } \\
& \text { 3: gapping in chaining and chained purposive constructions } \\
& \checkmark
\end{aligned}
$$

4: coreference marking in chaining, nonfinite complementation, reflexivization

(7) Examples (square bracketing means 'not applicable'):

1+2: Jacaltec (relativization/interrogation on S or O only; Van Valin 1981)

[1+] 2: Plains Cree (quantifier launcher must be S/O; Dahlstrom 1986)

$[1+] 2+3$ : Dyirbal (S/O pivot in chaining and purposives; Dixon 1972)

Motivations, both formal and functional, for the hierarchy in (6) have been suggested in the literature. Possible functional motivations include the tight $\mathrm{O}$ Verb relation (responsible for VP's, idioms, etc.) motivating S/O control of agreement; relativization is most common on $S$ and O (Fox 1987), and this motivates $\mathrm{S} / \mathrm{O}$ control of focalization, interrogation, and other things commonly derived from or parasitic on relativization; cross-clausal coreference rests on topic continuity, and topics are mostly S/A (Givón 1983). A possible formal motivation (Manning 1996) is that control and reflexivization refer to a(rgument) structure, i.e. $<\mathrm{S}>$ or $<\mathrm{A}$, U $>$ with $\mathrm{A}$ [ctor] always higher than $\mathrm{U}$ [ndergoer], while all other constructions refer to $\mathrm{f}$ (unctional) structure, e.g. $<$ PIVOT, COMPL $>$ with variable a-to-f mapping.

However, Belhare and Chechen-Ingush infinitive complementation reverse this hierarchy, showing syntactic ergativity in complementation and nowhere, or almost nowhere, else. This reversal is in conflict with all theoretical claims we are aware of, whether formal or functional.

\section{Toward an Explanation}

The key to understanding this unexpected pattern of syntactic ergativity comes from the observation that the matrix verbs involved are light verbs with a partly underspecified argument structure ('arg-structure'): while their A-role must be filled by a referent (and is often thematically specified by the light verb itself), these verbs also open up a semantically unrestricted object (' $O$ ') slot which can be filled by a propositional expression (of the type she wants that they do this), but whenever this is possible, the slot is preferably filled by an element contained in the arg-structure of a dependent (subcategorized) verb. ${ }^{3}$

In the following, 'lower verb' or 'lower arg-structure' refers to the dependent verb, whose arg-structure provides the filler of the O-slot in the light verb. Lower

\footnotetext{
${ }^{3}$ The formal mechanism involved is best explicated as ARGUMENT COMPOSITION (cf., among others, Monachesi 1998 and Melnik 2000), but we leave elaboration of this point for another occasion. Here we focus on the typological facts that give rise to syntactic ergativity.
} 
arg-structures are notated by lower case role labels (e.g. <a,o>), light verb argstructures by upper case role labels (e.g., $\langle\mathrm{A}, \mathrm{O}\rangle$ ). Cross-linguistically common instances of partly underspecified light verbs have phasal (begin, stop, continue etc.), modal (can, must, may, etc.), or cognitive (want, see, think, etc.) semantics.

There are two ways in which the lower arg-structure can satisfy the light verb's O-slot: by arg-structure unification, or by long-distance agreement. Both these options have particular lexical implementations that give rise to syntactic ergativity in complementation.

\subsection{Argument Structure Unification}

Unification of arg-structures results in clause union (complex predicate formation) and implies a single set of grammatical relations. There are many ways in which this can be achieved constructionally, e.g. through causative-style clause union that adds a grammatical relation, but the construction relevant for our purposes involves identification of the lower s or a-argument with the light verb's A-argument.

While the A-argument in the light verb is identified with the lower s or aargument, the underspecified O-slot can be filled by a lower argument if there is one. This can occur only if the lower verb is transitive and thus contains an oargument. ${ }^{4}$ This is schematically explicated in (8), where the underspecified Oslot is represented by an underscore:

(8) Syntax:

Arg-structure: $\quad<\mathrm{a}, \mathrm{o}>+<\mathrm{A}, \quad>=<\mathrm{A}(=\mathrm{a}), \mathrm{O}(=\mathrm{o})>$

If the lower verb is intransitive, however, its only argument ('s') is already identified with the A-argument, and there is no other lower argument available that could fill the O-slot (cf. Haspelmath 1999 for a simular observation):

(9) Syntax:

Arg-structure: $\quad<\mathrm{s}>+<\mathrm{A}, \ldots=<\mathrm{A}(=\mathrm{s}), \stackrel{ }{\longrightarrow}>$

As long as the the light verb has transitive syntax, the empty O-slot still needs to be satisfied. The only available candidate for this is the lower verb (or VP) as a whole, and this is indeed what characterizes a typologically common kind of Agreement Climbing construction.

This kind of Agreement Climbing is found, for example, in Spanish (and some other Romance languages). In Spanish, the O-slot of light verbs is generally satisfied through a proclitic in agreement with the lower o-argument. The lower aargument is identified with the A-argument (10a):

${ }^{4}$ In ditransitives, the o-argument is the argument that maps into the direct or primary object. 


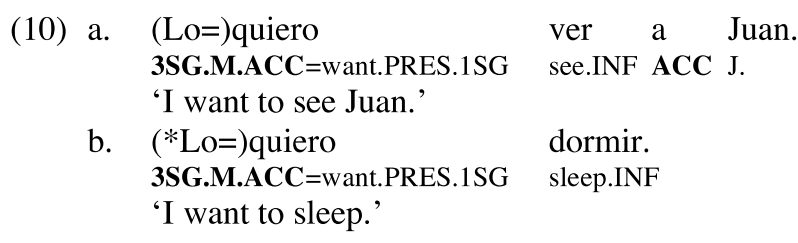

Agreement Climbing as in (10a) is generally optional, but in some dialects, e.g. in Argentinian Spanish, it is virtually obligatory (Fernando Zuñiga, p.c.). As shown by (10b), lower intransitive verbs cannot provide fillers of the O-slot. In this case, it is, as predicted, the VP (dormir 'sleep') as a whole that satisfies the O-slot. This does not result in an agreeement-indexing proclitic ( $l o=$ 'him') because only specific nominal referents can trigger object agreement in Spanish.

A similar pattern is found in Basque (Iraide Ibarretxe, p.c.), but in this language, lower intransitive VPs are registered as third person singular objects by the agreement morphology of the light verb. This is shown by (11a); (11b) exemplifies $\mathrm{O}$-agreement with the lower o-argument of a transitive dependent verb:

(11) a. (Nik) etxe-ra etorr-i nahi dut.

1SG.ERG house-ALL come-PERF want 3SG.O:PRES:1SG.A

'I want to come home'

b. (Nik) liburu-a-k eros-i nahi ditut.

1SG.ERG book-DET-PL[-NOM] buy-PERF want 3PL.O:PRES:1SG.A

'I want to buy the books'

Essentially the same pattern of Agreement Climbing as in Spanish or Basque is found in a typologically widespread variety of languages, including Daghestanian (e.g., Haspelmath 1999 on Godoberi) and Indo-Aryan languages (e.g., Butt 1993 and Bickel \& Yadava 2000 on Hindi). It is also found in Chechen and Ingush, where it characterizes modal verbs, e.g. Chechen:

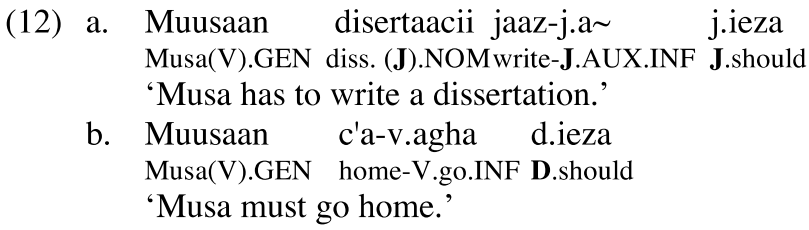

The Chechen light verb d.ieza 'should, must' shows O-agreement with a lower oargument, but if the lower verb is intransitive, the light verb shows default Dgender agreement.

Superlight verbs and transitivity agreement

In all of the instances surveyed in (10) - (12), the light verb has a fixed syntactic valence: it is always inflected transitively and governs the same transitive case 
frame regardless of whether the lower verb is transitive or intransitive. However, some languages, have SUPERLIGHT verbs which assimilate in valence to the lower verb. Superlight verbs allow extension of Agreement Climbing to lower intransitive verbs:

(13) a. Syntax:

Arg-structure:

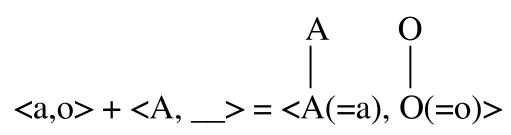

b. Syntax:

Arg-structure:<smiles>S=C=[Si](S)=[V]</smiles>

If the lower verb is transitive, as in (13a), the superlight verb has a transitive valence, and arg-structure unification proceeds just as with ordinary light verbs. If the lower verb is intransitive, as in (13b) however, the superlight verb has an intransitive arg-structure and an intransitive case syntax. The lower s-argument is now identified with $\mathrm{S}$ and can trigger $\mathrm{S}$-agreement. The underspecified $\mathrm{O}$-slot is removed.

Superlight verbs are found in Basque, Belhare, Chechen and Ingush. A Basque example is the verb ahal 'can, be possible'; other modal verbs such as behar 'must' behave alike in the spoken language, but transitivity agreement is proscribed by the Academy (Iraide Ibarretxe, p.c.):

(14) a. (Nik) liburu-a-k eros-i ahal ditut.

1SG.ERG book-DET-PL[-NOM] buy-PERF can 3PL.O:PRES:1SG.A

'I can buy the books.'

b. (Ni) etxe-ra etorr-i ahal naiz.

1SG.NOM house-ALL come-PERF can 1SG.S:PRES

'I can come home.'

If the lower verb is transitive, as in (14a), the superlight verb is inflected transitively, and just as with ordinary light verbs, its O-slot is satified by the lower oargument ('books') through agreement. But if the lower verb is intransitive, as in (14b), it is inflected intransitively and has intransitive case syntax (unlike with ordinary light verbs, cf. (11a)). As predicted by (13b), the S-function realizes the lower s-argument.

The same type of superlight verbs is found in Belhare. The verbs lapma 'be about to' and hima 'already V, be able to V' have this syntactic behavior:'

${ }^{5}$ See Bickel (2001, in press) for further discussion of infinitival complements in Belhare. 

(15) a. unna han lu-ma n-lapt-he-ga i? 3SG.ERG 2SG.NOM tell-INF 3[SG]A-be.about.to-PT-2[sg.O] Q 'Was s/he about to tell you?'
b. unchik ta-ma n-lap-yu $/ *$ n-lap-t-u. 3NSG.NOM come-INF 3NSG.S-be.about.to-NPT 3NSG.A-about.to-NPT-3[SG]O 'They are about to come.'

As shown by the ungrammaticality of the transitively inflected form nlaptu in (15b), valence agreement is obligatory. The resulting S-agreement marker realizes the lower s-argument, and the case on the subject is nominative, as predicted.

Transitivity deponence and syntactic ergativity

The syntax observed in (14) and (15) is nearly ergative: the superlight verb agrees with the lower o or s-argument. It is not fully ergative because the agreement markers are formally different: O-agreement in the case of a lower o-argument, and $\mathrm{S}$-agreement in the case of a lower s-argument. However, full-fledged syntactic ergativity emerges if transitivity agreement is morphologically invisible, i.e. if it has only syntactic effects but no concomitant effects in verb morphology. This arises if the superlight verb has DEPONENT morphology. By deponent morphology (or deponence tout court) we understand any lexically marked mismatch of morphological and syntactic properties (see Corbett 2000, Bickel \& Nichols, in press). The classic example of deponence is Latin verbs with transitive active syntax that lack active inflectional morphology and have only passive inflectional paradigms. Similarly, deponent superlight verbs are verbs with transitive or intransitive syntax that lack the corresponding inflectional morphology.

Belhare has both all-transitive deponent superlight verbs, which lack intransitive paradigms but show transitivity agreement in the syntax, and all-intransitive deponent superlight verbs, which lack transitive paradigms but show transitivity agreement in the syntax. The following illustrates one of five superlight verbs that are all-transitive deponents (the others are talokma 'begin', manma 'finish', munditma 'forget', and nima 'know'):

(16) a. unna han lu-ma n-tog-he-ga.

3SG.ERG 2SG.NOM tell-INF 3[SG]A-can-PT-2[SG.O]

'He had a chance to tell you.'

b. unchik ta-ma n-tou-t-u.

3NSG.NOM come-INF 3NSG.A-can-NPT-3[SG]O

'They can come.'

(16a) illustrates the transitive version of the superlight verb, and the syntax is exactly the same as with regular superlight verbs (cf. (15a)): the lower o-argument triggers O-agreement in the superlight verb. In (16b), the superlight verb tokma 'can, have the opportunity to' agrees in transitivity with the lower intransitive verb, and this has the syntactic effects that the lower s-argument can trigger 
agreement and that the case on the subject is nominative. However, instead of the expected INTRANSITIVE inflectional form (*ntokyu), the superlight verb shows TRANSITIVE morphology, and S-agreement is realized by the morphology of Aagreement. (17) makes this explicit on the basis of the same arg-structure and syntax as in (13b):

(17) Morphology:

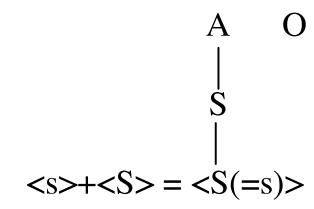

The O-agreement in the form ntoutu 'they can' is syntactically frozen (just as the passive morpheme in a Latin deponent is syntactically frozen), and the third person singular default form in $-u$ is the only one possible whenever the lower verb is intransitive.

With all-intransitive superlight deponent verbs, the expected pattern is the one with intransitive lower verbs: the superlight verb has intransitive syntax and morphology, and its S-agreement marker cross-references the lower s-argument. This is illustrated by (18a). The unexpected pattern is the one in $(18 b)(=(1 a))$.

(18) a. (han) khon-ma nui-ka. 2SG.NOM play-INF may-NPT:2[SG]S

'You may play.'

b. (unchikna) (han) lu-ma nui-ka.

3NSG.ERG 2SG.NOM tell-INF may-NPT:2[SG]S

'They may tell you.' Impossible: 'You may tell them.'

In (18b) the superlight verb has transitive case syntax, but instead of the expected $\mathrm{O}$-agreement morphology that would cross-reference the $\mathrm{O}(=0)$ argument in the composite arg-structure, we find intransitive morphology; the relevant transitive paradigm is simply lacking:

(19) Morphology:

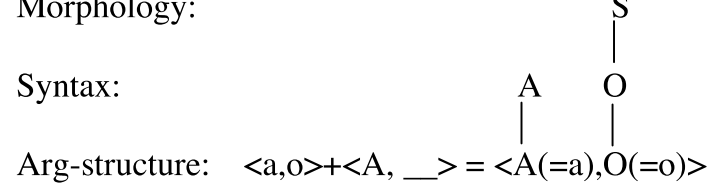

Why is it the O-function, and not the A-function, that has a morphological reflex in (19)? If it were the A-function, the structure would be indistinguishable from a construction in which the O-slot was filled by the dependent verb ('you may [they tell you]'), and neither arg-structure unification nor the $\mathrm{O}=\mathrm{o}$ argument resulting therefrom could possibly have a retrievable syntactic effect. The only way in 
which this is possible and in which the lower o can fill the O-slot in an all-intransitive deponent verb is through the mapping shown in (19).

The result of this, however, is syntactic ergativity: the lower s-argument in (18a) triggers exactly the same kind of agreement in the superlight verb as the lower o-argument in (18b).

Ancillary evidence for this analysis is twofold. First, the case marking found in (18b) confirms that the syntax is transitive despite the intransitive morphology of the superlight verb: there is no other situation in Belhare where intransitively inflected verbs combine with an ERGATIVE-NOMINATIVE case frame. Likewise, in (16b), the case frame is intransitive despite the transitive morphology, and again, there is no other situation in Belhare where a NOMINATIVE-only case frame could co-occur with a transitively inflected verb. It is only in these lexically marked instances of transitivity deponence that there can be a mismatch between case and agreement morphology.

Second, deponence is an independently attested phenomenon in Belhare and many of its sister languages. Experiential predicates like khikma 'taste bitter', for example, are all-intransitive deponents that have two syntactic actants, an experiencer in A-function and a stimulus in O-function (see Bickel 1999 and in press for discussion of the syntactic properties of these actants). Belhare's sister language Limbu has experiential predicates that are all-transitive but that have an intransitive syntax (Michailovsky 1997).

The analysis proposed for Belhare essentially carries over to Ingush and Chechen. There are regular superlight verbs undergoing transitivity agreement. Transitive infinitives may and preferably do trigger transitive auxiliaries in the superlight verb; intransitive infinitives must have intransitive auxiliaries (cf. Melnik 2000 for Chechen):

(20) a. Laqa juola-jyr.

play.INF J.start-J.TRANS.AUX.WP

'She started playing [the instrument (J-gender)].'

b. Chaarx c'eaxxaa qesta juola-jalar.

wheel(J) suddenly turn.INF J.begin-J.INTR.AUX.WP

'The wheel suddenly started turning.'

With a transitive lower verb, as in (20a) the superlight verb is inflected intransitively (on its auxiliary) and agrees with the $\mathrm{O}=0$ actant, following the pattern in (13a). If the lower verb is intransitive, as in (20b), the superlight verb is intransitive as well and agrees with the lower s-argument ('wheel' (J gender)).

Chechen and Ingush also have a few superlight verbs that are similar to Belhare superlight deponents. One of them, d.ieza 'should', is illustrated in the Chechen example (3) above. Unlike the superlight verbs (about 4 in total) illustrated for Ingush in (20), these deponent verbs have the same effect of syntactic ergativity as we observed in Belhare: syntactically, they assimilate in transitivity, 
whence agreement is with the lower s- or o-argument; but morphologically, this is invisible, and the agreement morphology always takes the same form. However, unlike in Belhare, the transitive vs. intransitive distinction is not an obligatory property of Ingush morphology. It is only apparent if verbs take an auxiliary, as they do in (20). The verb in (3a) is a simplex verb. Therefore, the reason why this verb does not manifest morphologically visible transitivity agreement is that it does not take an auxiliary and not that it lacks parts of a paradigm. We call this a QUASI-DEPONENT.

And, as in Belhare, transitivity deponence is found independently in other parts of the Ingush (and Chechen) lexicon as well. The Ingush verbs qeika-d.u 'cough' and qoa-d.u 'find time, manage' are always inflected transitively (i.e. take transitive auxiliaries), yet they have intransitive valence with one single actant.

\subsection{Long-Distance Agreement}

In the scenario described so far, the restriction of matrix $\mathrm{O}$ agreement to lower o arguments results from the fact that the lower s- or a-argument is coreferential with the higher A argument, hence unavailable as filler of the O-slot in the light or superlight verb. However, some Kiranti languages (e.g., Belhare) and some NakhDaghestanian languages (e.g., Tsez) extend the same type of light verb complementation, with the same type of matrix agreement, to disjoint s/a-arguments. The result is yet another complementation construction with a syntactically strictly ergative pivot.

In these cases, clauses are not unified but preserve two distinct sets of grammatical relations. However, the empty object slot in the light verb is satisfied by an argument from the lower clause through LONG-DISTANCE AGREEMENT (Polinsky \& Comrie 1999). Example (21) illustrates this for Tsez:

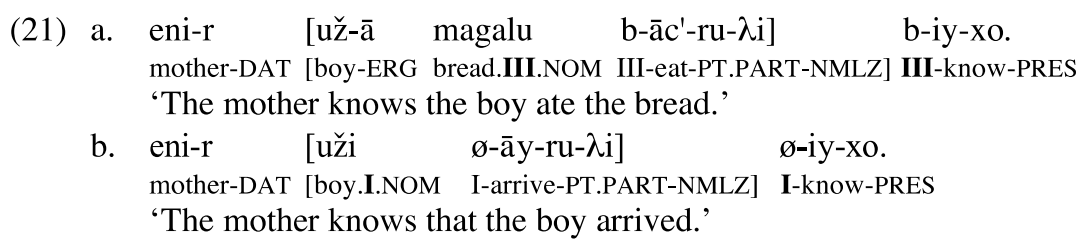

As Polinsky \& Potsdam (in press) show, the structure of these sentences is biclausal; yet it is the lower a (21a) or the lower s (21b) argument that is recruited to fill the O-slot in the light verb's arg-structure through long-distance agreement. Note that in contrast to the clause union constructions discussed earlier, the lower a-argument $u \check{z} \bar{a}$ 'boy' in (21a) is not integrated into the light verb's arg-structure. It is only s and o arguments that can trigger long-distance agreement, and this is another source for syntactic ergativity in light verb complementation.

A similar construction is found in Belhare with the light verbs konma 'want' and nama 'stop': 
(22) a. khali [set-ma] ka-n-koĩ-yu. only kill-INF 1INCL.O-3NSG.A-want-NPT 'They just want us to get drunk.' (lit., 'they want [the beer] kill us.')

b. [ten-ma] ma-n-narend-he. beat-INF 1SG.O-3NSG.A-stop-PT 'They stopped $\mathrm{x}$ from beating me.' or 'They stopped beating me.'

In these examples, the lower verb is transitive and its o-argument fills the light verb's O-slot through agreement. The lower a-argument (that which 'kills' in (22a), the person(s) who beat in (22b)) is not syntactically identified with the light verb's A-argument. This is again in contrast with the constructions involving argstructure unification.

However, note that while the lower a-arguments in (22) are not SYNTACTICALLY identified with the higher A-arguments, they are left unexpressed, and in a suitable context, the lower a-arguments can be PRAGMATICALLY identified with the A-arguments (cf. the alternate translation of (22b)). Indeed, the most common usage of konma 'want' and nama 'stop' relies precisely on this interpretation. A likely reason for this is that Belhare infinitives do not allow antipassive formation, so that a syntactic constraint AGAINST $\mathrm{a}=\mathrm{A}$ identification would make it impossible to have topic continuity in such ordinary clauses as 'he wants to buy beer' or 'she stopped drinking beer'.

Thus, though a and A can be distinct, they most often are coreferential, and this assimilates the construction to arg-structure unification as discussed earlier. Belhare long-distance agreement constructions indeed seem to be developing into clause union constructions. Independent evidence for this comes from the fact that konma 'want' and nama 'stop' allow (partly) optional transitivity agreement, the hallmark of superlight verbs and arg-structure unification. Thus, along with the transitive version of konma 'want', intransitive inflection is possible too (23a). With lower intransitives, intransitive inflection is obligatory (23b):

(23) a. lu-ma kõ̃-yu.

tell-INF [3SG.S-]want-NPT

'He wants to tell.' or ' $\mathrm{He}_{i}$ wants $\mathrm{x}$ to tell him $_{i, j}$ '

b. ta-ma koĩ-yu /*mai-koĩ-yu $/ *$ koĩ-t-u.

come-INF [3SG.S-]want-NPT 1SG.O-[3SG.A-]want-PT [3SG.A]want-NPT-3SG.O]

'He wants to come.' or 'He wanted x to come.'

However, unlike with superlight verb constructions, the lower a or s-argument still does not have to be coreferential with the A-argument of konma 'want'.

The asymmetric distribution of transitive and intransitive versions in (23) is the same as the one observed in Chechen and Ingush (see discussion of example (20) above), and results from the fact that all these languages are base-intransitive languages, where the intransitive forms are the default, and transitives the derived forms (Nichols et al. 1999). 


\section{Syntactic Ergativity in Light Verb Complements}

\section{Conclusions and Implications}

The findings presented here suggest that, despite common assumptions to the contrary, true ergative syntax is possible in complementation structures. It is possible if a language has either (i) deponent superlight verbs that allow extension of argstructure unification to intransitives, or (ii) long-distance agreement. While in option (ii) there is no intrinsic need for syntactic ergativity to arise, option (i) appears to necessitate ergativity because, as we showed in Section 3.1, the unification construction that deponent superlight verbs rely on have an intrinsic bias to take the lower o or s arguments as fillers of the superlight verb's empty O-slot. The a-argument is unavailable because it is identified with the superlight verb's A-argument.

Thus, type (i) syntactic ergativity is the result of specific lexical properties in argument structure (light vs. superlight verbs) and morphology (deponence). This suggests that universal hierarchies of the likelihood of syntactic ergativity may be successfully relativized to lexical properties.

\section{Abbreviations}

2SG second person singular; 3PL third person plural, etc; I, III Tsez genders; A subject of transitives; ACCusative; ALLative; AUXiliary; CAUSative; DATive; DETerminer; ERGative; GENitive; INFinitive; J a Chechen-Ingush gender; LATive; M masculine gender; NMLZ nominalizer; NOMinative; NPT nonpast; NSG nonsingular; $\mathrm{O}$ (primary or direct) object of transitives; PARTiciple; PERFect;; PRESent; PT past; S single argument of intransitives; TRANSitive; V a Chechen-Ingush gender; WP witnessed past. Elements in square brackets are features expressed by zero morphemes; '=' denotes a clitic boundary.

\section{Acknowledgments}

NSF 96-16448 (JN, PI) (Chechen, Ingush). Arbi Vagapov (Chechen examples).

SNSF 8210-053455 (BB, PI) (Belhare). Lekh Bāhadur Rāī (Belhare examples).

\section{References}

Bickel, B. 1999. Grammatical relations, agreement, and genetic stability. Ms., University of California, Berkeley.

Bickel, B. 2001. Belhare. In G. Thurgood and R. J. LaPolla, eds., The SinoTibetan languages. London: Curzon Press.

Bickel, B. In press. Hidden syntax in Belhare. In G. van Driem, ed., Himalayan Linguistics. Berlin: Mouton de Gruyter.

Bickel, B., and J. Nichols. In press. Inflectional morphology. In T. Shopen, ed., Language Typology and Syntactic Description. Cambridge: Cambridge University Press (revised second edition).

Bickel, B., and Y. P. Yadava. 2000. A fresh look at grammatical relations in IndoAryan. Lingua 110: 343-73. 
Butt, M. 1993. A reanalysis of long distance agreement in Urdu. In J. Guenter, B. Kaiser, and C. Zoll, eds., Proceedings of the Nineteenth Annual Meeting of the Berkeley Linguistics Society, 52-63. Berkeley, CA: Berkeley Linguistics Society.

Conathan, L. 2001. Ergative and binominative constructions in Ingush. Ms., University of California, Berkeley.

Corbett, G. G. 2000. Four inflectional phenomena and the notion 'possible lexical item'. Paper presented at the Northwest Slavic Linguistics Conference, Berkeley, CA.

Croft, W. 1991. Syntactic Categories and Grammatical Relations. Chicago: University of Chicago Press.

Dahlstrom, A. L. 1986. Plains Cree morphosyntax. Ph.D. diss., University of California, Berkeley.

Dixon, R. M. W. 1972. The Dyirbal Language of North Queensland. Cambridge: Cambridge University Press.

Dixon, R. M. W. 1994. Ergativity. Cambridge: Cambridge University Press.

Fox, B. 1987. The noun phrase accessibility hierarchy reinterpreted: Subject primacy or the absolutive hypothesis? Language 63: 856-70.

Givón, T., ed. 1983. Topic Continuity in Discourse. Amsterdam: John Benjamins.

Givón, T. 1997. Introduction. In T. Givón, ed., Grammatical Relations, 1-84. Amsterdam: John Benjamins.

Haspelmath, M. 1999. Long-distance agreement in Godoberi (Daghestanian) complement clauses. Folia Linguistica 33: 131 -51.

Manning, C. D. 1996. Ergativity: Argument Structure and Grammatical Relations, Stanford, CA: CSLI.

Melnik, N. 2000. Agreement climbing in Chechen: An HPSG analysis. Ms., University of California, Berkeley.

Michailovsky, B. 1997. Catégories verbales et intransitivité duale en Limbu. Studi Italiani di Linguistica Teoretica e Applicata 26: 307-25.

Monachesi, P. 1998. Italian restructering verbs: A lexical analysis. In E. Hinrichs, A. Kathol, and T. Nakazawa, eds., Syntax and Semantics Vol. 30: Complex Predicates in Nonderivational Syntax, 313-68. New York: Academic Press.

Nichols, J., D. A. Peterson, and J. Barnes. 1999. Causativizing and decausativizing languages. Association for Linguistic Typology Meeting, Amsterdam.

Polinsky, M., and B. Comrie. 1999. Agreement in Tsez. Folia linguistica 33: 4-25.

Polinsky, M., and E. Potsdam. In press. Long-distance agreement. Natural Language and Linguistic Theory.

Van Valin, R. D., Jr. 1981. Grammatical relations in ergative languages. Studies in Language 5: 361-94. 